\title{
Mechanical circulatory support as bridge therapy for heart transplant: case series report
}

\author{
Javier D. Garzon-Rodriguez ${ }^{1}$, Carlos Obando-Lopez ${ }^{2}$, Manuel Giraldo-Grueso $3^{*} \mathbb{0}$, Nestor Sandoval-Reyes ${ }^{2}$, \\ Jaime Camacho and Juan P. Umaña²
}

\begin{abstract}
Background: Mechanical circulatory support (MCS) represents an effective urgent therapy for patients with cardiac arrest or end-stage cardiac failure. However, its use in developing countries as a bridge therapy remains controversial due to costs and limited duration. This study presents five patients who underwent MSC as bridge therapy for heart transplantation in a developing country.

Case presentation: We present five patients who underwent MCS as bridge therapy for heart transplant between 2010 and 2015 at Fundación Cardioinfantil-Instituto de Cardiología. Four were male, median age was 36 (23-50) years. One patient had an ischemic cardiomyopathy, one a lymphocytic myocarditis, two had electrical storms (recurrent ventricular tachycardia) and one an ischemic cardiomyopathy with an electrical storm. Extracorporeal life support (ECLS) was used in three patients, left ventricular assistance in one, and double ventricular assistance in one (Levitroni ${ }^{\circledR}$ Centrimag $\left.^{\circledR}\right)$. Median assistance time was 8 (2.5-13) days. Due to the inability of cardiopulmonary bypass weaning, two patients required ECLS after transplant. One patient died in the intensive care unit due to type I graft rejection. Endpoints assessed were 30-day mortality, duration of bridge therapy and complications related to MCS. Patients that died on ECLS, or were successfully weaned off ECLS were not included in this study.
\end{abstract}

Conclusions: MCS is often the only option of support for critically ill patients waiting for a heart transplant and could be considered as a short-term bridge therapy.

Keywords: Heart-assist devices, Extracorporeal membrane oxygenation, Heart transplantation, Myocardial ischemia

\section{Background}

The increase of life expectancy and ischemic heart disease within the years has created long heart transplant waiting lists. According to the United Network for Organ Sharing, more than 3000 hearts per year are needed to meet the waiting list demand in the United States; however, less than 2000 heart donors per year are reported [1]. In Colombia the median waiting list time for a heart transplant was 59 (1-606) days in 2014 [2]. The use of extracorporeal life support (ECLS) and ventricular assist devices as a bridge therapy for a heart transplant has been described as a feasible alternative [1-4]. However,

\footnotetext{
*Correspondence: mgiraldog@cardioinfantil.org

${ }^{3}$ Vascular Function Research Laboratory, Fundación CardioinfantilInstituto de Cardiología, Calle 163 A número 13B-60, 111831 Bogotá, Colombia

Full list of author information is available at the end of the article
}

the cost of the therapy, the success rate and the limited duration of ECLS remain as subjects of concern [1-4]. We present five cases of mechanical circulatory support (MSC) as a bridge therapy for a heart transplant and the short-term results.

\section{Case presentation}

From January of 2010 to December 2015, five patients underwent ECLS or ventricular assist devices as bridge therapy for heart transplantation at Fundación Cardioinfantil-Instituto de Cardiología, Bogotá-Colombia. Patients that died on ECLS, or were successfully weaned off ECLS are not presented. The ventricular assist device used was the Levinotrix ${ }^{\circledR}$ CentriMag $^{\circledR}$ (levitronix LLC; waltham, mass).

The indications for MCS were: Ischemic cardiomyopathy, lymphocytic myocarditis, and an electrical storm 
(recurrent ventricular tachycardia). The interagency registry for mechanically assisted circulatory support (INTERMACS) was assessed in all patients. The primary endpoints were 30-day mortality, duration of bridge therapy and complications related to MCS.

Four patients were male. All patients were New York heart association class IV. The median left ventricular ejection fraction was 19\% (15-20). One patient had an ischemic cardiomyopathy, one a lymphocytic myocarditis, two had electrical storms and one an ischemic cardiomyopathy with an electrical storm (Table 1 ).

Before MCS, three patients required inotropic support; four patients had an intra-aortic balloon pump. One patient had mechanical ventilatory support and three had organ dysfunction (acute kidney failure). All patients underwent catheter ablation therapy due to rhythm abnormalities. Four patients were INTERMACS 1 and one INTERMACS 2 . One patient presented transit ischemic attack (right-side hemiparesia that disappear within $1 \mathrm{~h}$, without medical therapy) (Table 1).

During MCS, one patient required left ventricular assistance, two ECLS, and one biventricular assistance. The median time of MCS prior to heart transplantation was 8 (2.5-13) days. Two patients had vascular complications

\section{Table 1 Patient characteristics}

\begin{tabular}{|c|c|c|c|c|c|}
\hline Variables & Case 1 & Case 2 & Case 3 & Case 4 & Case 5 \\
\hline \multicolumn{6}{|l|}{ Demographic and clinical } \\
\hline Age (mean, SD) & 50 & 21 & 51 & 25 & 36 \\
\hline Male & No & Yes & Yes & Yes & Yes \\
\hline Hypertension & Yes & No & Yes & No & Yes \\
\hline Chronic kidney disease & No & No & No & Yes & Yes \\
\hline Diabetes mellitus & No & No & No & No & Yes \\
\hline $\operatorname{LVEF}(\%)$ & 15 & 19 & 20 & 21 & 16 \\
\hline INTERMACS 1 & Yes & Yes & Yes & Yes & No \\
\hline INTERMACS 2 & No & No & No & No & Yes \\
\hline Myocarditis & No & No & No & Yes & No \\
\hline Electrical storm & Yes & Yes & No & No & No \\
\hline Ischemic cardiomyopathy & Yes & No & Yes & No & Yes \\
\hline \multicolumn{6}{|l|}{ MCS support } \\
\hline ECLS & Yes & No & No & Yes & Yes \\
\hline Ventricular assistance & No & Yes & Yes & No & No \\
\hline Vascular complications & Yes & No & Yes & No & No \\
\hline Time (days) & 8 & 2 & 15 & 3 & 11 \\
\hline \multicolumn{6}{|l|}{ Post-transplant } \\
\hline Graft rejection & No & No & No & No & Yes \\
\hline Reoperation for bleeding & No & No & No & Yes & No \\
\hline Mortality & No & No & No & No & Yes \\
\hline Stroke & Yes & No & No & No & No \\
\hline ECLS & Yes & No & No & No & Yes \\
\hline Intra-aortic balloon pump & Yes & No & Yes & Yes & Yes \\
\hline
\end{tabular}

during MCS, one developed leg ischemia; the other one required a surgical exploration due to bleeding at the insertion site of the femoral cannulae (Table 1).

After the heart transplant, four patients continued with an intra-aortic balloon pump, and two required ECLS due to the inability of cardiopulmonary bypass weaning. Two patients developed a pericardial effusion; both of them required a percutaneous drainage. One patient developed a hemopericardium that was managed through a sternotomy. One patient died in the intensive care unit due to type 1 graft rejection and multiple organ dysfunctions (Table 1).

\section{Discussion and conclusions}

MCS is a useful alternative for the management of critically ill patients with cardiogenic shock, refractory cardiac failure or potentially fatal arrhythmias [5-11]. In Latin America, there are no publications describing the use of ECLS and ventricular assist devices as a bridge therapy for heart transplantation, and adult patients are rarely bridged to transplantation due to difficulties in the urgent medical evaluation. Therefore this study contributes to an emerging field and could indicate ECLS and ventricular assist devices are a feasible bridge for a heart transplant.

All the patients we described received MCS as a bridge for transplant. Waiting time for organ availability was short since the average duration of the bridge therapy was 8 days. Some studies described the need for at least 3 weeks of ECLS before transplant [3]. However, poor outcomes are reported with prolonged use of ECLS, the frequency of bleeding, infection or embolism begins to rise after the first 7 days [4]. In our series, all patients were listed as high-urgency.

Recent studies have shown good results after a heart transplant in patients with preoperative ECLS [8-11]. Pre-existing organ dysfunction elevated blood urea, and liver function are significant predictors of death. Therefore if the patient has multiple organ failures the bridge therapy should not be considered $[4,12]$.

The prognosis after heart transplant seems to be superior in patients with INTERMACS 1, which underwent ECLS at an early stage [13]. In our series, we showed that all patients INTERMACS 1 accomplished hemodynamic stabilization during ECLS therapy that enabled them to achieve a successful heart transplant.

Patients in our series, were young (median age 36 years) had a poor functional class, a low left ventricular ejection fraction (median 19\%) and biventricular failure with pulmonary edema. Barth and colleagues [3] reported a cohort of 8 patients with bridge therapy, the mean left 
ventricular ejection fraction was $17.5 \%$, the mean age was 49 years and they also had a poor functional class.

Ischemic cardiomyopathy is the most common indication for a heart transplant [3]. In our series we found a high frequency of electric storms, these patients received a conservative inotropic management and underwent ECLS due to the high risk of sudden death. Two patients had vascular complications during MCS, one developed leg ischemia; the other one required a surgical exploration due to bleeding at the insertion site of the femoral cannulae. In both patients, the cannulae was adjusted and no motor deficits were observed.

In our series, we found a high incidence of bleeding reoperations. Three patients developed cardiac tamponade secondary to hemopericardium or pericardial effusion, which was managed with pericardiocentesis or a median sternotomy. This is higher than the previously reported series, which describes $28 \%$ of bleeding reoperations [8]. Ranjit and colleagues [14] reported a $4 \%$ frequency of infectious complications, although our series have only five patients, it is worth noting that the freedom from infectious complication was $100 \%$.

Only one patient died after heart transplant as a result of a type 1 graft rejection which evolved to multisystemic organ failure. This condition is associated with a high mortality rate (almost $80 \%$ ) despite optimal treatment, or retransplantation [2].

MCS is often the only option of support for critically ill patients (refractory heart failure, cardiogenic shock or electric storm) needing a heart transplant. We suggest considering ECLS and ventricular assist devices as a short-term bridge therapy, since the mechanic support becomes a real alternative due to hemodynamic stabilization and gives time to find a heart donor. However, patients in ECLS have more complications, especially with increasing duration of use.

\section{Abbreviations \\ ECLS: extracorporeal life support; INTERMACS: the interagency registry for mechanically assisted circulatory support; MCS: mechanical circulatory support.}

\section{Authors' contributions}

$J U, J C, N S, C O, J G$ were the cardiac surgeons in charge of the patients and made important intellectual contributions. MG made substantial contributions to conception, design, and data acquisition. JG and MG structured the article and were involved in drafting the manuscript and revising it critically for important intellectual content. All authors read and approved the final manuscript.

\section{Author details}

${ }^{1}$ Universidad del Rosario, Fundacion Cardioinfantil-Instituto de Cardiología, Bogotá, Colombia. ${ }^{2}$ Cardiac Surgery Department, Fundación CardioinfantilInstituto de Cardiología, Bogotá, Colombia. ${ }^{3}$ Vascular Function Research Laboratory, Fundación Cardioinfantil-Instituto de Cardiología, Calle 163 A número 13B-60, 111831 Bogotá, Colombia.

\section{Acknowledgements}

We will like to thank the anesthesia department and the research department for the advisory and corrections for this manuscript.

\section{Competing interests}

The authors declare that they have no competing interests.

\section{Availability of data and materials}

The datasets used and/or analyzed during the current study are available from the corresponding author on reasonable request.

\section{Consent for publication}

Written informed consent was obtained from study participants for participation in the study and for publication of this report. Consent and approval for publication was also obtained from the "Comité de ética en investigación clínica" of Fundación Cardioinfantil-Instituto de Cardiología Bogotá-Colombia.

\section{Ethics approval and consent to participate}

All patients gave their permission to allow their information to be used in this case report. The manuscript was approved by the institutional review board "Comité de Ética en Investigación Clínica".

Funding

No funding was obtained for this study.

\section{Publisher's Note}

Springer Nature remains neutral with regard to jurisdictional claims in published maps and institutional affiliations.

Received: 27 December 2017 Accepted: 19 June 2018

Published online: 03 July 2018

\section{References}

1. Wever-Pinzon O, Drakos SG, Kfoury AG, et al. Morbidity and mortality in heart transplant candidates supported with mechanical circulatory support. Circulation. 2013;127(4):452-62.

2. Informe anual Red de Donación y Trasplantes, Colombia. 2014. https:// www.researchgate.net/publication/296846836_Informe_anual_Red_de_ Donacion_y_Trasplantes_Colombia_2014. Accessed 04 Mar 2018.

3. Bertolotti Alejandro M, Peradejordi Margaret A, Favaloro L, et al. Experience with magnetic centrifugal pump in patients with cardiogenic shock (INTERMACS level 1). Rev Argent Cardiol. 2014;82:205-10.

4. Barth E, Durand M, Heybroeck C, Rossi-Blancher M, Boignard A, et al. Extracorporeal life support as a bridge to high urgency heart transplantation. Clin Transplant. 2012;26(3):484-8.

5. Lim HS, Howell N, Ranashinghe A. Extracorpotral life support: physiological concepts and clinical outcomes. J Card Fail. 2017;23(3):181-96.

6. Napp LC, Kühn C, Hoeper MM, et al. Cannulation strategies for percutaneous extracorporeal memebrane oxiygenatio in adults. Clin Res Cardiol. 2016;105(4):283-96.

7. Alba Ana C, McDonald M, Rao V, et al. The effect of ventricular assist devices on long-term post-transplant outcomes: systematic review of observational studies. Euro J Heart Fail. 2011;13:785-95.

8. Borisenko O, Wylie G, Payne J, et al. Thoratec CentriMag for temporary treatment of refractory cardiogenic shock or severe cardiopulmonary insufficiency: a systematic literature review and meta-analysis of observational studies. ASAIO. 2014;60:487-4978.

9. Kolla S, Lee WA, Hirschl R, Bartlett R. Extracorporeal life support for cardiovascular support in adults. ASAIO J. 1996:42:M809-19.

10. Tseng PH, Wang SS, Chang CL, Shih FJ. Perceived health-related quality of life in heart transplant recipients with vs without preoperative ECMO in Taiwan: between method triangulation study. Transplant Proc. 2010;42:923-6.

11. Fumagalli $R$, Bombino $M$, Borelli $M$, et al. Percutaneous bridge to heart transplantation by venoarterial ECMO and transaortic left ventricular venting. Int J Artif Organs. 2004;27:410-3.

12. Brunet $D$, Eltchaninoff $H$, Kerkeni $M$, et al. Mechanical circulatory assistance in myocardial infarction with refractory cardiogenic shock: clinical 
experience in 10 patients at a teaching hospital in Rouen. Arch Cardiovasc Dis. 2008;101:30.

13. Stevenson LW, et al. INTERMACS profi les of advanced heart failure: the current picture. J Heart Lung Transplant. 2009;28(6):535-41.
14. Ranjit J, Pagani FD, Naka Y, Boyle A, Conte J, Russell S, et al. Post-cardiac transplant survival after support with a continuos-flow left ventricular assist device: impact of duration of left ventricular assist device support and other variables. JThorac Cardiovasc Surg. 2010;140:174-81.
Ready to submit your research? Choose BMC and benefit from:

- fast, convenient online submission

- thorough peer review by experienced researchers in your field

- rapid publication on acceptance

- support for research data, including large and complex data types

- gold Open Access which fosters wider collaboration and increased citations

- maximum visibility for your research: over 100M website views per year

At BMC, research is always in progress.

Learn more biomedcentral.com/submissions 